\title{
Fabric formwork with ice in Canada.
}

\section{STRUCTURAL MEMBRANES 2021}

\author{
Arno PRONK*, Mahboobeh Fakhrzareie ${ }^{\dagger}$, Abolfazl Ashrafie ${ }^{\dagger}$ \\ * Eindhoven University of Technology, Faculty of Built environment, The Nederlands, \\ e-mail: a.d.c.pronk@tue.nl \\ https://www.tue.n1/en/research/researchers/arno-pronk/ \\ ${ }^{\dagger}$ Department of Civil and Environmental Engineering, University of Alberta
}

\begin{abstract}
In 2020 Pronk organized a workshop with students at the University of Alberta in Canada. They have been working outside since before dawn; mixing a slurry of water and paper together, pouring the resulting concoction into a prestressed foil fixed on a wooden frame and smoothing it as it freezes. Pronk estimates that his reinforced ice can be as much as three times stronger than regular frozen water. Usually, ice is very brittle, but adding fibre like paper or wood pulp makes it stronger and ductile. The fibre also acts as an insulator, and ensures the ice does not melt as fast. The materials are cheap and natural. Therefore, they do not harm the environment. In this case, the fiber used to create these ice beams is toilet paper.
\end{abstract}

The next day, the team removed the ice beams from their fabric mold. Both V-shaped beams were a little over six centimeters thick. The sun was just visible over the horizon as they propped up each beam with pieces of wood placed under the ends. Students took turns adding concrete blocks on top - creating a "point load," to determine how much weight each beam could hold. The skinnier beam took 600 pounds before it crumbles, while the larger one took 780 pounds before succumbing to the bricks.

Pronk sees the future of building with ice in projects that need to be strong but can be hard to clean up, such as temporary foundations for drilling rigs. He also says it might have future applications, such as research on Mars, where the environment is very cold. This project with Canadian engineering students might inspire them to new possibilities in cold climates.

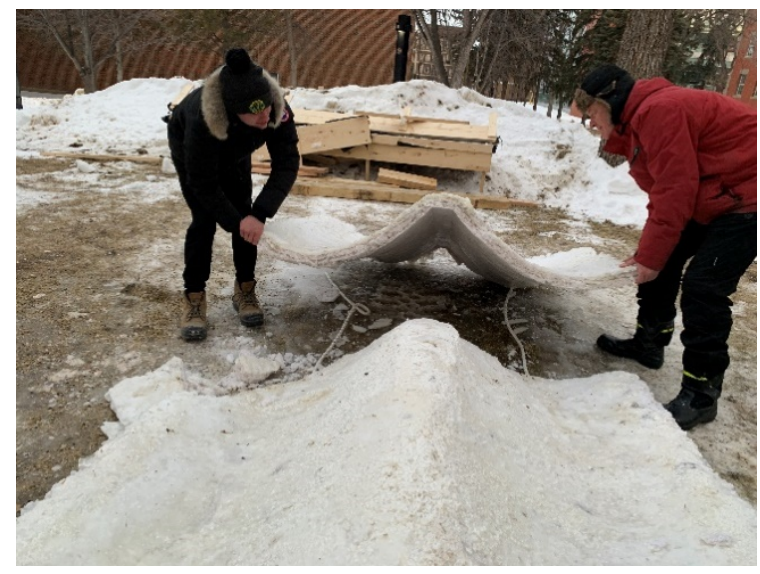

\section{REFERENCES}

[1] Pronk, A., Luo, P., Li, Q., Sanders, F., Overtoom, M., \& Coar, L. (2017, September). Success factors in the realization of large ice projects in education. In Proceedings of IASS Annual Symposia (Vol. 2017, No. 9, pp. 1-10). International Association for Shell and Spatial Structures (IASS).

[2] Pronk, A., Mistur, M., Li, Q., Liu, X., Blok, R., Liu, R., ... \& Dong, Y. (2019, April). The 201718 design and construction of ice composite structures in Harbin. In Structures (Vol. 18, pp. 117127). Elsevier. 